\title{
Jefferson
}

Thomas Jefferson University

$\overline{\text { HOME OF SIDNEY KIMMEL MEDICAL COLLEGE }}$

JHN Journal

Volume 14

Issue 1 Summer 2019

Article 4

Summer 2019

\section{Minimal Access Expandable Mesh Device for Transforaminal Lumbar Interbody Fusion: A Case Series}

Ryan Moncman, DO

Philadelphia College of Osteopathic Medicine

Michael Yoon, MD

Thomas Jefferson University

Follow this and additional works at: https://jdc.jefferson.edu/jhnj

\section{Let us know how access to this document benefits you}

\section{Recommended Citation}

Moncman, DO, Ryan and Yoon, MD, Michael (2019) "Minimal Access Expandable Mesh Device for Transforaminal Lumbar Interbody Fusion: A Case Series," JHN Journal: Vol. 14 : Iss. 1 , Article 4. DOI: https://doi.org/10.29046/JHNJ.014.1.004

Available at: https://jdc.jefferson.edu/jhnj/vol14/iss1/4

This Article is brought to you for free and open access by the Jefferson Digital Commons. The Jefferson Digital Commons is a service of Thomas Jefferson University's Center for Teaching and Learning (CTL). The Commons is a showcase for Jefferson books and journals, peer-reviewed scholarly publications, unique historical collections from the University archives, and teaching tools. The Jefferson Digital Commons allows researchers and interested readers anywhere in the world to learn about and keep up to date with Jefferson scholarship. This article has been accepted for inclusion in JHN Journal by an authorized administrator of the Jefferson Digital Commons. For more information, please contact: JeffersonDigitalCommons@jefferson.edu. 


\section{Minimal Access Expandable Mesh Device for Transforaminal Lumbar Interbody Fusion: A Case Series}

\author{
Ryan Moncman, DO1; Michael Yoon, MD² \\ ${ }^{1}$ Department of Neurological Surgery, Philadelphia College of Osteopathic Medicine, \\ Philadelphia, PA, 19131 \\ 2 Department of Neurological Surgery, Abington Hospital - Jefferson Health, Abington, PA, 19001
}

\begin{abstract}
Bone-sparing techniques for transforaminal lumbar interbody fusion (TLIF) are promoted to help maintain spinal stability and to minimize operative time. We present a series of seven patients who underwent TLIF with use of an interbody expandable mesh device and with supplemental instrumentation. This device is deployed and filled with bone through a small cannula. All patients experienced pain relief and suffered no complications. Our results support the data from other centers which have performed similar procedures with this device.
\end{abstract}

Keywords: transforaminal lumbar interbody fusion, OptiMesh, deployable mesh, minimal access

\section{INTRODUCTION}

Lumbar interbody devices can be difficult to insert from a posterior approach due to their sizes and shapes, especially when the disc space is significantly collapsed (Figure 5). In addition, stabilizing posterior elements are removed in order to create a clear corridor to the disc space. A less invasive approach to the disc space involves the placement of a collapsed, expandable mesh pouch (OptiMesh by Spineology, St. Paul, MN). The pouch is gradually filled with increasing amounts of allograft bone chips through the small portal. (Figure 1) The mesh itself is made out of polyethylene terephthalate, a non-absorbable and pliable material commonly used in vascular grafts. We describe a series of patients who underwent this procedure with supplemental instrumentation.

Spineology OptiMesh graft containment system has been approved for the treatment of stable vertebral body defects. The device has also been used in the disc space for interbody fusion. ${ }^{2,5,6,7,8,9}$ The OptiMesh portal, despite its low profile, allows for an extensive discectomy and with preparation of the endplates, especially when the

\begin{tabular}{|c|c|c|c|c|}
\hline \multicolumn{2}{|c|}{ Patient Info } & TLIF level, type & Follow up & Outcome Compared to Pre-op \\
\hline 1. & 66 yo $F$ & L2-3 open & 29 months & $90 \%$ overall pain relief \\
\hline 2. & 49 yo $M$ & L3-4 open & 24 months & $95 \%$ overall pain relief \\
\hline 3. & 73 yo $F$ & L1-2 open & 18 months & 90-95\% overall pain relief \\
\hline 4. & 66 yo $M$ & L4-5 open & 17 months & $80-85 \%$ overall pain relief \\
\hline 5. & 42 yo $M$ & L5-S1 open & 5 months & $50 \%$ overall pain relief \\
\hline 6. & 57 yo $F$ & L4-5 percutaneous & 3 months & $95 \%$ overall pain relief \\
\hline 7. & 46 yo $M$ & L4-5 percutaneous & 4 weeks & $\begin{array}{c}\text { Preoperative lower } \\
\text { extremity pain resolved. }\end{array}$ \\
\hline
\end{tabular}

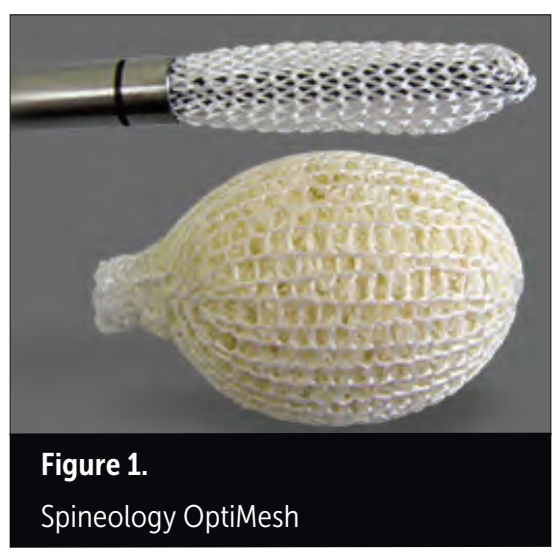

cannulas are introduced bilaterally. The bone chips are packed into the mesh until good filling of the disc space is noted on fluoroscopic imaging.

\section{CASE PRESENTATIONS}

From August 2016 through January 2019, seven patients underwent lumbar transforaminal interbody fusions by the senior author using the mesh containment device with supplemental instrumentation, either interspinous clamps (Patients 2, 3 and 5) or bilateral pedicle screws/rods (Patients 1,4,6 and 7). Five patients had the interbody device placed with some minimal bony removal. Two patients had the mesh inserted via a purely percutaneous, bone-sparing approach via Kambin's triangle (Figures 2 and 3). ${ }^{4}$ We utilized neuromonitoring for the percutaneous approaches.

Patient 1 was a 66-year-old female who presented with five years of low back pain and one year of right lower extremity pain. An MRI revealed retrolisthesis of $L 2$ on L3, which had progressed slightly over seven years. There were stable findings of anterolisthesis at L4-5 and at L5-S1.

Patient 2 was a 49 -year-old male with many years of back pain with one year of paresthesias and numbness in the bilateral lower extremities. An MRI showed 

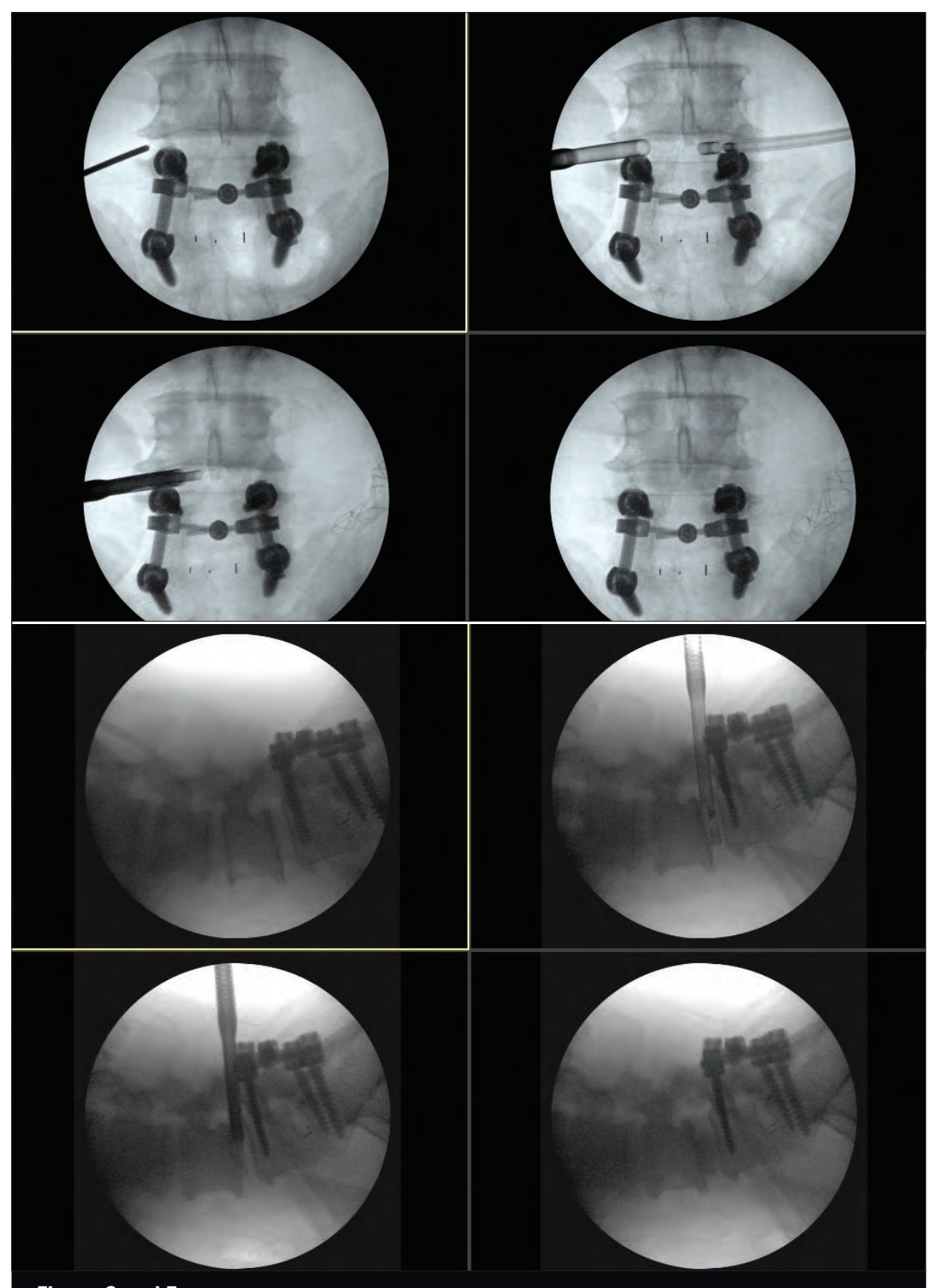

Figure 2 and 3.

Intraoperative fluoroscopic images on patient number 7 show the percutaneous instrumentation being placed into the bilateral disc spaces via Kambin's triangle. The disc is removed and the endplates prepared. The OptiMesh is then introduced and filled gradually with granular bone graft.

a moderate left-sided L3-4 disc/osteophyte complex with severe degenerative collapse and Modic changes. Similar findings, to a lesser degree, were seen at L5-S1.
Patient 3 was a 73-year-old female who had undergone an emergent laminectomy at an outside institution for sudden-onset bilateral lower extremity weakness three months earlier. She regained her strength and sensation but her preoperative, chronic low back pain and left lower extremity pain had worsened after the procedure. An MRI revealed very severe degenerative disc disease at L1-2 with Modic changes. Also noted were postoperative changes at $L 4$ to $\mathrm{S1}$

Patient 4 was a 66-year-old male with chronic lower back pain which had worsened over six months. He also complained of bilateral lower extremity weakness when going up or down stairs. Physical exam revealed no objective weakness. An MRI revealed a grade I spondylolisthesis at L4-5 with Modic changes and moderate central stenosis.

Patient 5 was a 42-year-old male with a history of end-stage renal disease and had presented to the hospital with severe, intractable low back pain radiating into the left lower extremity. An MRI showed evidence of a discitis at L5-S1 and cultures from a needle biopsy by interventional radiology grew Staphylococcus epidermidis. Despite initial antibiotic treatment and narcotic medications, he remained in severe intractable pain. He did have a history of chronic low back pain.

Patient 6 was a 57-year-old female who had undergone a right hemilaminectomy and bilateral sublaminar decompression at L4-5. She continued to have bilateral lower extremity pain two months after surgery, and dynamic radiographs had demonstrated abnormal motion at L4-5.

Patient 7 was a 46 -year-old male who had undergone an L5-S1 instrumented interbody fusion nine years ago. He had developed progressive low back and bilateral lower extremity pain, left greater than right. An MRI showed some mild degenerative disc disease at L4-5 but dynamic radiographs revealed instability at this level with a solid fusion at L5-S1. This particular patient required revision of his existing hardware in order to couple it to the new pedicle screws which were inserted into L4. However, the interbody mesh was delivered via an entirely percutaneous approach.

All patients experienced pain relief compared to preoperatively with no complications (nerve root injuries, durotomies, infections, or hardware failures). All 


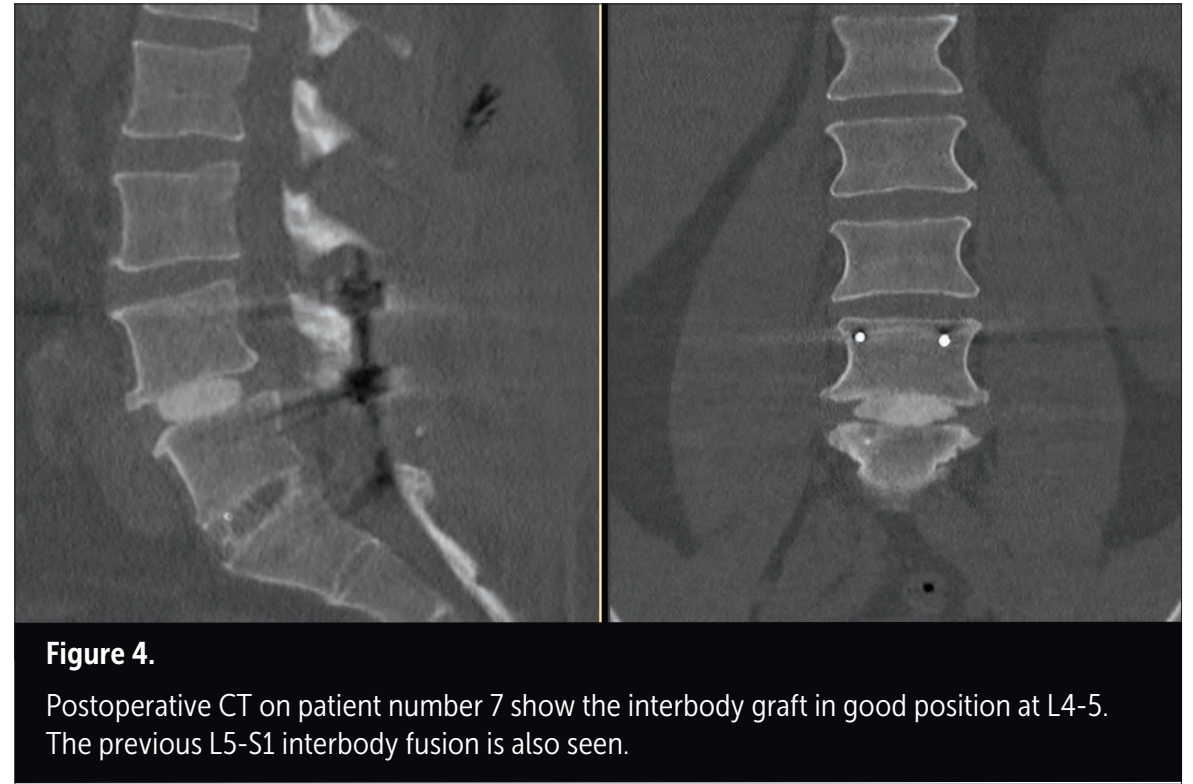

patients, except for number 5 , had failed conservative management including physical therapy and/or epidural steroid injections. Follow up ranged from 2 weeks to 28 months.

\section{DISCUSSION AND CONCLUSIONS}

In order to place a typical interbody cage via a TLIF, the unilateral facet joint is generally removed in its entirety. Standard TLIF cages measure from $7 \mathrm{~mm}$ to $16 \mathrm{~mm}$ in height with 10 to $11 \mathrm{~mm}$ width. The Spineology OptiMesh cannula measures $7 \mathrm{~mm}$ in diameter; all the bone chips that fill the mesh are delivered through this size portal. The mesh allows for much less bony removal and also the option of a purely percutaneous approach requiring no bony removal via a trajectory through Kambin's triangle.

The rigidity and contour of most interbody devices often causes undesired trauma to the vertebral endplates during insertion. Weakening of the endplates could contribute to settling of bone over the interbody construct. The mesh appears to conform well to a patient's unique endplate shape and integrity (Figure 7). Moreover, the density of the inserted bone chips should more closely match that of a patient's own bone than polyetheretherketone (PEEK) or metal, theoretically reducing the risk of subsidence.

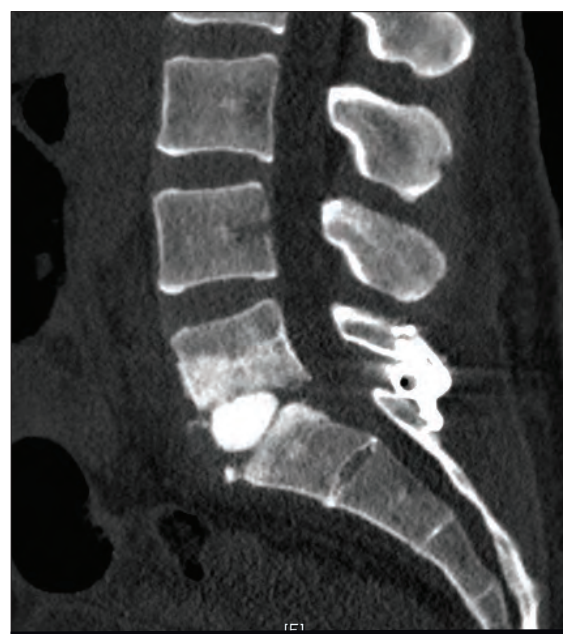

Figure 6.

Postoperative CT on patient number 4. The placement of the interbody graft is in the anterior disc space and the lordosis is maintained. Such placement of a graft would be difficult to achieve from a posterior approach with a traditional interbody device due to the narrow entry point through the dorsal disc space. Lordotic cages have a leading edge which are larger than the tail end.

Various expandable interbody cages are available, but most devices expand only in the sagittal plane, not in the axial and coronal ones. The OptiMesh expands in all planes and, as mentioned, contours to

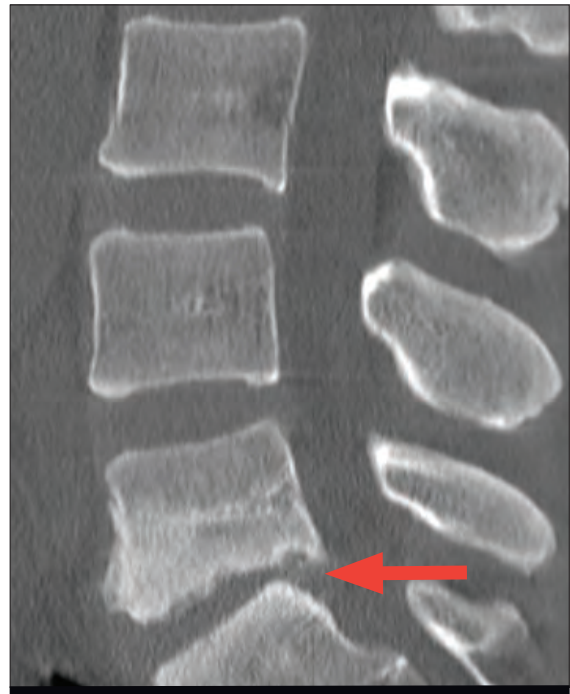

\section{Figure 5.}

Preoperative $\mathrm{CT}$ on patient number 4. Arrow points to narrow corridor for insertion of a TLIF cage.

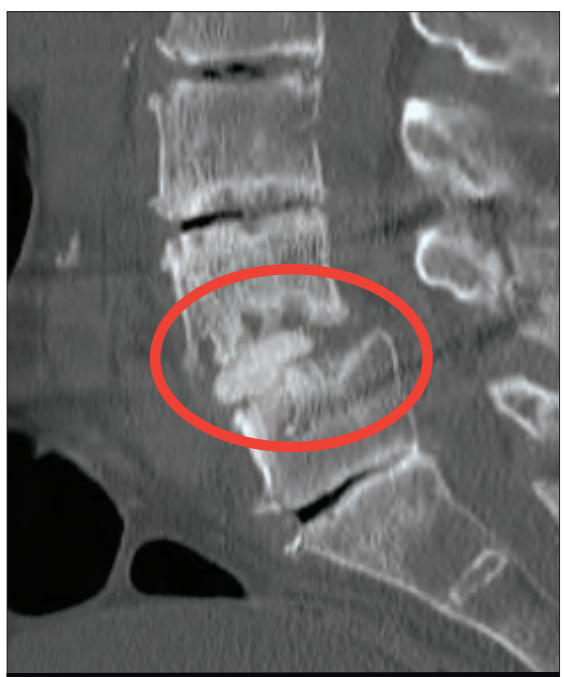

Figure 7.

Postoperative CT scan on patient number 6 shows the mottled appearance of the endplates with the OptiMesh device within the disc space. The unhealthy endplates make placement of a very rigid device undesirable.

the shape of the actual disc space. The PEEK or metal used in most interbody devices also occupy significant space, whereas the mesh allows for more surface area contact for bone to remodel 
and potentially increase the likelihood of a robust bony fusion.

Based on our limited experience, the mesh device is a safe, effective option for TLIF. Its main advantages appear to be decreased anatomical disruption during delivery and deployment, the ability to expand in all planes with conformity to the endplates, and greater surface area contact of bone for remodeling and fusion. A study involving a larger number of patients and further long-term follow up is warranted.

\section{REFERENCES}

1. Chiu JC, Maziad AM: Post-traumatic Vertebral Compression Fracture Treated with Minimally Invasive Biologic Vertebral Augmentation for Reconstruction. Surg Technol Int. 1:268-77, 2011
2. Hsuan-Kan Chang, John Paul G Kolcun, Peng-Yuan Chang, Michael Y Wang; Enhanced Recovery After Surgery ${ }^{\mathrm{TM}}$ Awake Minimally-Invasive Transforaminal Lumbar Interbody Fusion: 2-Dimensional Operative Video, Operative Neurosurgery, opy187, https://doi.org/10.1093/ons/opy187

3. Inamasu J, Guiot BH, Uribe JS: Flexiondistraction injury of the L1 vertebra treated with short-segment posterior fixation and Optimesh. J Clin Neurosci. 15(2):214-8, 2008

4. Kambin P, Sampson S. Posterolateral percutaneous suction-excision of herniated lumbar intervertebral discs. Report of interim results. Clin Orthop Relat Res. 1986;207:37-43

5. Krag, M (2009): Prospective Evaluation of a Conformable Interbody Bone Graft Container Presented at The International Society for the Study of the Lumbar Spine. Miami, FL.
6. Nucci, R (Nov 2010): Outpatient Instrumented Anterior/Posterior Lumbar Fusion. Presented at Society for Minimally Invasive Spine Surgery. Miami, FL.

7. Perez-Cruet $M$, Lauryssen $\mathrm{C}$, Krag $\mathrm{M} \mathrm{H}$, et al (2006): Novel Expandable Interbody Fusion Device: Results of a Multicenter IDE Feasibility $\&$ Safety Study. Presented at the College of Neurological Surgeons. Chicago, IL.

8. Zahrawi F (April 2010), Minimally Invasive Fusion Using Deployable Mesh Filled with Allograft and BMP. Presented at The Annual Global Symposium on Motion Preservation Technology. New Orleans, LA.

9. Zheng, Xiujun et al. Biomechanical evaluation of an expandable meshed bag augmented with pedicle or facet screws for percutaneous lumbar interbody fusion. The Spine Journal. 10(11): 987 - 993, 2010 